\title{
Total Thrombus-Formation Analysis System (T-TAS): Clinical Application of Quantitative Analysis of Thrombus Formation in Cardiovascular Disease
}

\author{
Koichi Kaikita ${ }^{1}$ Kazuya Hosokawa ${ }^{2}$ Jeffrey R. Dahlen ${ }^{3}$ Kenichi Tsujita ${ }^{1}$ \\ ${ }^{1}$ Department of Cardiovascular Medicine, Graduate School of Medical \\ Sciences, Kumamoto University, Kumamoto, Japan \\ 2 Research Institute, Fujimori Kogyo Co., Yokohama, Kanagawa, Japan \\ ${ }^{3}$ Hikari Dx, San Diego, California, United States \\ Address for correspondence Koichi Kaikita, MD, PhD, Department of \\ Cardiovascular Medicine, Graduate School of Medical Sciences, \\ Kumamoto University, 1-1-1, Honjo, Chuo-ku, Kumamoto, 860-8556, \\ Japan (e-mail: kaikitak@kumamoto-u.ac.jp).
}

Thromb Haemost 2019;119:1554-1562.

\begin{abstract}
Keywords

- T-TAS

- antiplatelet therapy

- direct oral anticoagulants

- antithrombotic therapy

- diagnostic test

Various antithrombotic agents are clinically used to inhibit the cascade of arterial or venous thrombosis in cardiovascular diseases. Dual antiplatelet therapy with aspirin and $\mathrm{P}_{2} \mathrm{Y}_{12}$ inhibitors is prescribed in patients with coronary artery disease (CAD) undergoing percutaneous coronary intervention ( $\mathrm{PCl}$ ). Direct oral anticoagulants (DOACs) are widely used for the prevention or treatment of thromboembolism in patients with atrial fibrillation (AF) and venous thromboembolism. However, there has been no definitive tool to simultaneously monitor the antithrombotic effects of these drugs. The Total Thrombus-Formation Analysis System (T-TAS), a microchip-based flow chamber system that mimics in vivo conditions for evaluating whole blood thrombogenicity, was developed for the quantitative analysis of thrombus formation in whole blood specimens. The utility of T-TAS has been evaluated in CAD patients treated with antiplatelet therapies. The T-TAS PL chip area under the flow pressure curve (AUC) accurately assesses primary hemostasis and is sensitive to the therapeutic effects of various antiplatelet therapies. In addition, low AUC results are a significant predictor of periprocedural bleeding events in CAD patients undergoing PCI. The T-TAS AR chip AUC result is useful for assessing the efficacy of DOACs and warfarin in AF patients undergoing catheter ablation, and it is also a potential independent predictor of periprocedural bleeding events and avoidance of thrombosis in patients having undergone total knee arthroplasty. In conclusion, T-TAS is a useful index for evaluating the total antithrombotic effects of combination antithrombotic agents in patients with various cardiovascular diseases.
\end{abstract}

\section{Introduction}

Arterial and venous thrombosis play an important role in the pathogenesis of various cardiovascular diseases, and several pharmacological agents are clinically used to inhibit the cascade of thrombus formation. Antiplatelet agents repre- sent the mainstay preventive strategy against systemic arterial thrombosis, as platelets play crucial roles in initiating thrombus formation. ${ }^{1-3}$ Dual antiplatelet therapy (DAPT) with aspirin and $\mathrm{P}_{2} \mathrm{Y}_{12}$ receptor inhibitors is established in patients with acute coronary syndrome or after received

December 23, 2018

accepted after revision

May 29, 2019
DOI https://doi.org/

10.1055/s-0039-1693411. ISSN 0340-6245. (c) 2019 Georg Thieme Verlag KG
Stuttgart · New York
License terms

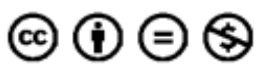


percutaneous coronary intervention (PCI). ${ }^{4-15}$ In contrast, anticoagulant drugs are widely used for prophylaxis and treatment of venous thrombosis. Direct oral anticoagulants (DOACs) are widely useful for the prevention or treatment of thromboembolism in patients with atrial fibrillation (AF) ${ }^{16-19}$ and venous thromboembolism (VTE). ${ }^{20-25}$ Several diagnostic devices have recently been developed to evaluate the pathogenesis and therapies related to thrombotic and hemorrhagic disorders. ${ }^{26-34}$

Recently, the Total Thrombus-Formation Analysis System (T-TAS), a microchip-based flow chamber system designed to evaluate thrombogenicity in whole blood, was developed as an easy-to-use system for quantitative analysis of thrombus formation. T-TAS can assess the influence of antithrombotic agents on platelet activation and coagulation reactions over a collagen or collagen/tissue thromboplastin-coated surface. ${ }^{35-41}$ Here, we compare the scientific principle of TTAS to other existing platelet function tests and review the use of T-TAS for measuring the antithrombotic effects of several antithrombotic agents in patients with various cardiovascular diseases.

\section{Measurement of Thrombogenicity by T-TAS}

As shown in the Virchow Triad, thrombosis is caused by a defect in blood flow, blood vessels, and/or blood components. T-TAS is an automated microchip-based flow chamber system developed for easy and quick assessment of platelet thrombus formation under physiological flow conditions, to approximate thrombus formation in vivo. ${ }^{35-41}$ This system analyzes different thrombus formation processes using a simple procedure comprising two microchips with different thrombogenic surfaces: a platelet (PL) chip specific for measuring primary hemostatic ability and an atheroma (AR) chip for measuring fibrin-rich platelet thrombus formation (-Table 1). The PL chip is coated with type I collagen, and platelets adhere via von Willebrand factor (vWF) to the surface of the collagen and aggregate inside the microchip, leading to occlusion of the microchip capillaries. The AR chip is coated with type I collagen plus tissue thromboplastin, which simultaneously activates platelets and the coagulation system, respectively, inside the microchip. The process of thrombus formation inside the chips can be analyzed by monitoring the change in flow pressure. The area under the flow pressure curve (AUC) was computed to assess the thrombogenicity inside the microchips. The AUC over 10 minutes is computed for the PL chip and the AUC over 30 minutes is computed for the AR chip. A version of the TTAS instrument called T-TAS Plus was developed for the research setting and has user-selectable flow rates and video capture capability. PL chip flow rates of 18 and $24 \mu \mathrm{L} / \mathrm{min}$ are defined as $\mathrm{PL}_{18}-\mathrm{AUC}_{10}$ and $\mathrm{PL}_{24}-\mathrm{AUC}_{10}$, which correspond to shear stresses of $1,500 \mathrm{~s}^{-1}$ and $2,000 \mathrm{~s}^{-1}$, respectively. A previous study showed the significant positive correlation between $\mathrm{PL}_{18}-\mathrm{AUC}_{10}$ and $\mathrm{PL}_{24}-\mathrm{AUC}_{10}$ (or simply, PL-AUC) levels in samples from the patients with cardiovascular disease. ${ }^{42}$ The AR chip is typically tested at a flow rate of $10 \mu \mathrm{L} / \mathrm{min}$, defined as $\mathrm{AR}_{10}-\mathrm{AUC}_{30}$ (or simply, AR-AUC), which corresponds to a shear rate of $600 \mathrm{~s}^{-1}$. An in vitro diagnostic version of T-TAS has been developed that uses fixed flow rates of 18 and $10 \mu \mathrm{L} / \mathrm{min}$ for the PL and AR chips, respectively, and does not contain video capture capabilities.

\section{Comparison of Methods for Various Platelet Function Assessments and T-TAS}

- Table 2 shows the comparison of various platelet function tests. Several assay systems have been developed to monitor antiplatelet treatment efficacy and to identify low responsiveness to therapies in clinical settings. ${ }^{26-32}$ Examples include the VerifyNow (Accriva Diagnostics, San Diego, California, United States) and Multiplate (Dynabyte Medical, Munich, Germany) systems, which measure platelet agglutination and aggregation in response to a soluble exogenous agonist, which is added for the purpose of rapidly activating all platelets in the blood sample being measured. These two platelet function tests analyze platelet aggregation and clot formation under nonflow conditions in response to a single platelet activation pathway activated by the soluble exogenous agonist. Because the agonists chosen are dependent on the purpose of the analysis (e.g., collagen or arachidonic acid are chosen for aspirin, adenosine diphosphate $[\mathrm{ADP}] \pm$ prostaglandin $\mathrm{E} 1$ is chosen for $\mathrm{P}_{2} \mathrm{Y}_{12}$ agonists, and ristocetin is chosen for von Willebrand disease), the results of these assays are agonistdependent and, therefore, provide information primarily related to the platelet activation pathway acted on by the exogenous agonist present in the assay. The PFA-100 test (Siemens Healthcare Diagnostics GmBH, Marburg, Germany) also quantifies platelet aggregate formation on the surface of collagen that is coated with a specific platelet agonist such as

Table 1 Technical characteristics of T-TAS assay chips

\begin{tabular}{|l|l|l|l|l|l|}
\hline Chip & Shear rates & Capillary coating & $\begin{array}{l}\text { Anticoagulants in } \\
\text { blood tube }\end{array}$ & Type of thrombi & Assay time \\
\hline PL chip & $\begin{array}{l}\text { Arterial } \\
1,000,1,500, \text { or } 2,000 / \mathrm{s}\end{array}$ & $\begin{array}{l}\text { Type } 1 \text { collagen } \\
\text { (pig tendon) }\end{array}$ & Hirudin or BAPA & Platelet thrombi & $\leq 10$ min \\
\hline AR chip & $\begin{array}{l}\text { Venous or arterial } \\
240 \text { or } 600 / \mathrm{s}\end{array}$ & $\begin{array}{l}\text { Type } 1 \text { collagen } \\
\text { (pig tendon) } \\
\text { Tissue thromboplastin } \\
\text { (rabbit brain) }\end{array}$ & Citrate & $\begin{array}{l}\text { Fibrin rich } \\
\text { platelet thrombi }\end{array}$ & $\leq 30$ min \\
\hline
\end{tabular}

Abbreviations: AR, atheroma; BAPA, benzylsulfonyl-D-Arg-Pro-4-amidinobenzylamide; PL, platelet; T-TAS, Total Thrombus-Formation Analysis System. 
Table 2 Comparison of whole blood methods for platelet function assessment

\begin{tabular}{|l|l|l|l|l|}
\hline & VerifyNow & Multiplate & PFA-100 & T-TAS PL chip \\
\hline Assay type & Pathway-specific assay & Pathway-specific assay & Pathway-dependent assay & Global assay \\
\hline Blood flow & Nonflow condition & Nonflow condition & Arterial flow condition & Arterial flow conditions \\
\hline $\begin{array}{l}\text { Platelet } \\
\text { activators }\end{array}$ & $\begin{array}{l}\text { Soluble exogenous } \\
\text { agonist(s) }\end{array}$ & $\begin{array}{l}\text { Soluble exogenous } \\
\text { agonist(s) }\end{array}$ & $\begin{array}{l}\text { Soluble exogenous agonist(s) } \\
\text { Collagen surface } \\
\text { Shear stress }\end{array}$ & $\begin{array}{l}\text { Collagen surface } \\
\text { Shear stress }\end{array}$ \\
\hline Analysis & $\begin{array}{l}\text { Agglutination } \\
\text { Aggregation }\end{array}$ & $\begin{array}{l}\text { Nonspecific adhesion } \\
\text { Aggregation }\end{array}$ & $\begin{array}{l}\text { Adhesion } \\
\text { Aggregation }\end{array}$ & Thrombus formation \\
\hline Parameters & $\begin{array}{l}\text { Pathway-specific } \\
\text { reaction units }\end{array}$ & $\begin{array}{l}\text { Area under the } \\
\text { impedance-time curve }\end{array}$ & Closure time & $\begin{array}{l}\text { Area under the flow } \\
\text { pressure-time curve }\end{array}$ \\
\hline
\end{tabular}

Abbreviations: PL, platelet; T-TAS, Total Thrombus-Formation Analysis System.

epinephrine or ADP to evaluate the effects of aspirin or $\mathrm{P}_{2} \mathrm{Y}_{12}$ receptor inhibitors under arterial shear conditions; however, the results of this assay are also agonist-dependent. Although these systems are less labor-intensive than light transmittance aggregometry and permit the use of whole blood, their results reflect platelet activity primarily based on the specific pathway activated by the soluble exogenous agonist, and they are insensitive to the contribution of other mechanisms for platelet activation. Therefore, while these tests are useful for assessing the activity or blockade of a particular platelet activation pathway, they are of limited utility for monitoring overall primary hemostasis. - Fig. 1 highlights the primary differences between the T-TAS PL assay and other available assays for measuring platelet activity within the scope of overall primary hemostasis. The PL assay reflects the three major steps in platelet thrombus formation: vWF-mediated platelet adhesion, the release of endogenous platelet agonists, and platelet activation and aggregation. While the PL assay is able to assess overall primary hemostasis, it is not able to specifically evaluate individual platelet activation pathways and cannot provide information about the reason for impaired primary hemostatic function. In this regard, the PL assay and agonist-based assays are complimentary and their combined use can provide a comprehensive analysis of primary hemostasis.

Further, while plasma-based prothrombin time (PT) and activated partial thromboplastin time (APTT) are commonly used to titrate warfarin and heparin for monitoring the efficacy of anticoagulant treatments, PT and APTT do not reflect the interaction between coagulation factors and platelets in vivo. Rotational thromboelastometry (ROTEM [Tem Innovations GmbH, Munich, Germany]) is frequently used to measure viscoelastic changes due to fibrin formation and platelet activation during thrombus formation in whole blood. $^{33}$ ROTEM is potentially useful for evaluating the antithrombotic effects of low molecular weight heparin, direct thrombin, or Xa inhibitors, ${ }^{34}$ although it is relatively insensitive for platelet function and not suitable for evaluating efficacy of antiplatelet agents. Additionally, a major limitation of ROTEM is the lack of blood flow that affects the supply and washout of platelets, coagulation factors, and inhibitors.

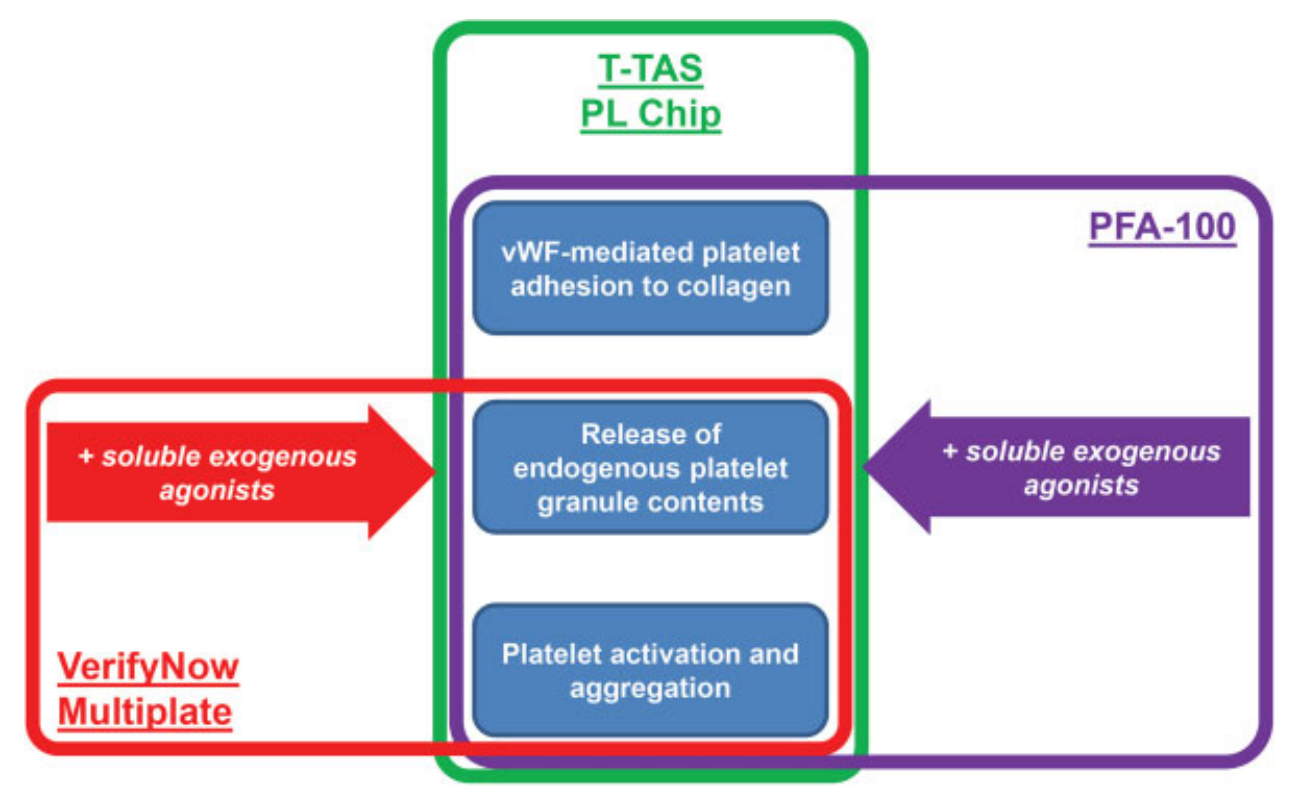

Fig. 1 Primary differences between the Total Thrombus-Formation Analysis System (T-TAS) platelet (PL) assay and other available assays for measuring platelet activity within the scope of overall primary hemostasis. 


\section{Assessment of Total Thrombogenicity in Patients with Coronary Artery Disease and Cerebrovascular Disease Treated with Various Antiplatelet Agents}

Antiplatelet therapy is used for the prevention of coronary artery disease (CAD) and cerebrovascular disease (CVD). Aspirin is used as the mainstay drug for secondary prevention of ischemic cardiovascular events ${ }^{43}$ and its concomitant use with platelet $\mathrm{P}_{2} \mathrm{Y}_{12}$ receptor inhibitors can reduce the risk of thrombotic events after stent implantation. ${ }^{4-15}$ Clopidogrel is a commonly used thienopyridine drug, and requires biotransformation to an active metabolite by the enzyme cytochrome P4502 C19 (cytochrome P-450 2C19 [CYP2C19]). ${ }^{44-47}$ In contrast, prasugrel is a third-generation thienopyridine used for the prevention of thrombotic cardiovascular events in patients with acute coronary syndrome undergoing PCI. ${ }^{48,49}$ Compared with clopidogrel, prasugrel has a faster onset of action, greater inhibition of platelet aggregation at clinical doses, and lower between-patient variability, ${ }^{45}$ suggesting that it may be effective in clopidogrel-poor responders and in CYP2C19 genetic variant carriers. Ticagrelor is another potent antiplatelet agent that reversibly binds to the platelet $\mathrm{P}_{2} \mathrm{Y}_{12}$ receptor. ${ }^{49}$

The efficacy of antiplatelet therapy can be assessed by several techniques. ${ }^{26-32}$ The VerifyNow assay is an easy-to- use point-of-care system in which increased light transmission is used to reflect agonist-induced platelet aggregation with fibrinogen-coated latex beads. VerifyNow can be used to assess efficacy and safety of different antiplatelet drugs by using different cartridges specific for $\mathrm{P}^{2} \mathrm{Y}_{12}$, aspirin, or glycoprotein IIb/IIla inhibitor. Using this system, the platelet response to aspirin and $\mathrm{P}_{2} \mathrm{Y}_{12}$ receptor inhibitors is expressed as aspirin reaction units (ARUs) and $\mathrm{P}_{2} \mathrm{Y}_{12}$ reaction units (PRUs), respectively, with the PRU level being influenced by CYP2C19 genotype ${ }^{50-53}$ and correlated with cardiovascular events. ${ }^{54}$

There have been several reports in the analyses of antiplatelet therapies comparing the PL chip and agonist-dependent platelet function tests. As shown in - Table 3, in a report of Arima et al, samples from patients with cardiovascular disease taking no antiplatelet medication (controls), treated with aspirin, and treated with DAPT were comparatively analyzed with VerifyNow PRU and PL chip. ${ }^{42}$ The PRU levels were lower in the aspirin/clopidogrel group than the control and aspirin groups, but there were no significant differences in PRU levels between the control and aspirin groups. On the other hand, the PL-AUC levels were significantly lower in the two antiplatelet therapy groups compared with the control group, and the level was significantly lower in the aspirin/ clopidogrel group than the aspirin group, which were mostly

Table 3 Studies evaluating antithrombotic therapies with T-TAS

\begin{tabular}{|c|c|c|c|}
\hline Study & Population (n) & Tests & Results \\
\hline Hosokawa et al, $2013^{55}$ & $\begin{array}{l}72 \text { ACS patients and } \\
\text { healthy control }\end{array}$ & $\begin{array}{l}\text { T-TAS PL chip } \\
\text { Multiplate }\end{array}$ & $\begin{array}{l}\text { PL chip AUC was decreased in aspirin-only patients, and } \\
\text { was further decreased in DAPT patients. Multiplate AUC } \\
\text { showed the same values for aspirin and DAPT groups } \\
\text { with arachidonic acid, and showed the same values for } \\
\text { controls and aspirin groups with ADP }\end{array}$ \\
\hline Arima et al, $2016^{42}$ & $\begin{array}{l}274 \text { patients } \\
\text { suspected CAD }\end{array}$ & $\begin{array}{l}\text { T-TAS PL chip } \\
\text { VerifyNow }\end{array}$ & $\begin{array}{l}\text { PL chip AUC was decreased with aspirin alone, and } \\
\text { decreased even further by DAPT. VerifyNow PRU was } \\
\text { lower in the DAPT group compared with the control } \\
\text { group but not with the aspirin group }\end{array}$ \\
\hline Yamazaki et al, $2016^{56}$ & $\begin{array}{l}94 \text { patients with } \\
\text { ischemic stroke }\end{array}$ & $\begin{array}{l}\text { T-TAS PL chip } \\
\text { VerifyNow }\end{array}$ & $\begin{array}{l}\text { PL chip AUC was lower in patients with DAPT compared } \\
\text { with aspirin or clopidogrel alone. Clopidogrel low } \\
\text { responders analyzed by PL chip AUC predicted carotid } \\
\text { or intracranial arterial stenosis } \\
\text { VerifyNow PRU in patients with DAPT and clopidogrel } \\
\text { alone showed similar values and were lower compared } \\
\text { than aspirin alone. VerifyNow ARU in patients with DAPT } \\
\text { and aspirin alone showed similar values and were lower } \\
\text { than clopidogrel alone }\end{array}$ \\
\hline Oimatsu et al, $2017^{66}$ & $\begin{array}{l}313 \text { CAD patients } \\
\text { with } P C l\end{array}$ & $\begin{array}{l}\text { T-TAS PL chip } \\
\text { VerifyNow }\end{array}$ & $\begin{array}{l}\text { AR chip AUC but not VerifyNow PRU was lower in patients } \\
\text { that experienced periprocedural bleeding during PCI }\end{array}$ \\
\hline Borst et al, $2018^{67}$ & $\begin{array}{l}40 \text { NSTEMI patients } \\
\text { with PCl }\end{array}$ & $\begin{array}{l}\text { T-TAS AR chip } \\
\text { TG }\end{array}$ & $\begin{array}{l}\text { AR chip AUC and TG reflected the effect of triple } \\
\text { antithrombotic therapy with DAPT and very low-dose } \\
\text { rivaroxaban post-PCI }\end{array}$ \\
\hline Ito et al, $2016^{73}$ & $\begin{array}{l}128 \text { AF patients } \\
\text { with CA }\end{array}$ & $\begin{array}{l}\text { T-TAS AR chip } \\
\text { PT/APTT }\end{array}$ & $\begin{array}{l}\text { AR chip AUC but not PT and APTT was lower in AF patients } \\
\text { with periprocedural bleeding after CA }\end{array}$ \\
\hline Sueta et al, $2018^{77}$ & $\begin{array}{l}38 \text { patients with } \\
\text { TKA }\end{array}$ & $\begin{array}{l}\text { T-TAS AR chip } \\
\text { PT/APTT }\end{array}$ & $\begin{array}{l}\text { AR chip AUC and PT/APTT were lower in the combination } \\
\text { therapy group } 7 \mathrm{~d} \text { after than before TKA }\end{array}$ \\
\hline
\end{tabular}

Abbreviations: ACS, acute coronary syndrome; ADP, adenosine diphosphate; AF, atrial fibrillation; APTT, activated partial thromboplastin time; AR, atheroma; ARU, aspirin reaction unit; AUC, area under the curve; CA, catheter ablation; CAD, coronary artery disease; DAPT, dual antiplatelet therapy; NSTEMI, non-ST-elevation myocardial infarction; PCI, percutaneous coronary intervention; PL, platelet; PRU, P2Y 12 reaction unit; PT, prothrombin time; T-TAS, Total Thrombus-Formation Analysis System; TG, thrombin generation; TKA, total knee arthroplasty. 
consistent with data from other clinical studies. ${ }^{55,56}$ In the DAPT group, the PL-AUC level was higher in poor metabolizers (PMs) with CYP2C19 polymorphism than in non-PMs. These findings suggest that the T-TAS PL-AUC level might be useful to assess the combined, overall therapeutic effects of multiple antiplatelet therapies, particularly since the values decreased as the potency of antiplatelet therapy increased.

Periprocedural bleeding events are one of the most common complications after $\mathrm{PCI}$, and patients with periprocedural bleeding have an increased risk of readmission for treatment of recurrent bleeding, major adverse cardiovascular events, and all-cause mortality compared to those without periprocedural bleeding. ${ }^{5-61}$ While the development of various bleeding avoidance strategies, such as the radial approach, vascular closure devices, and bivalirudin, has reduced the incidence of periprocedural bleeding after $\mathrm{PCI}$, the rate has remained relatively high in several studies. ${ }^{62-64}$ The incidence rate of major PCI-related periprocedural bleeding in Japanese patients with acute coronary syndrome is $4.8 \%$ for the femoral approach and $1.1 \%$ for the radial approach, and that of elective PCI for CAD is $2.2 \%$ for the femoral approach and $0.2 \%$ for the radial approach. ${ }^{65}$ However, it was unclear from previous studies how the combined antithrombotic effects by different types of drugs were associated with periprocedural bleeding events in CAD patients undergoing PCI. Oimatsu et al reported that PL-AUC levels were significantly lower in patients with than in those without such events, and that there was a significant association between low PL-AUC levels and periprocedural bleeding events as defined by the International Society on Thrombosis and Haemostasis. ${ }^{66}$

Yamazaki et al performed analysis of CVD patient samples on aspirin alone, clopidogrel alone, and DAPT with PL chip and VerifyNow system. The AUC for PL chip was lower for those in the DAPT group than those in the aspirin or clopidogrel alone group. In contrast, VerifyNow ARU in the aspirin and DAPT groups was the same, and VerifyNow PRU showed the same values in clopidogrel and DAPT patients, indicating that the results overall were very characteristic of an agonist (cartridge)dependent assay..$^{56}$ In this way, analysis of platelet thrombus formation with PL chip can comparatively evaluate the single and combined efficacies of aspirin and clopidogrel on platelet thrombus formation while VerifyNow system can only be used to analyze the separate effects of aspirin and clopidogrel.

In T-TAS PL chip analysis, poor responders to aspirin monotherapy had increased multiple platelet aggregates as analyzed by fluorescence-activated cell sorting. ${ }^{55}$ In addition, poor responders to clopidogrel monotherapy had increased rates of carotid or intracranial arterial stenosis. ${ }^{56} \mathrm{PL}$ chip AUC was a good predictor of patients with PM CYP2C19 reduced function genotypes in DAPT patients, and combined use of PRU further enhanced the discrimination. ${ }^{42}$ By using both a global assay such as the PL chip and one of the conventional agonist-dependent assays together, the information about both the inhibition of receptors and enzymes by individual drugs, and the effect on overall platelet thrombus formation, can be obtained, which could be useful from the viewpoint of selecting and tailoring appropriate antiplatelet therapy for individual patients.
Borst et al showed that fibrin-rich platelet thrombus formation in AR chip was significantly inhibited by triple antiplatelet therapy with aspirin, clopidogrel, and very low-dose rivaroxaban in patients with non-ST-elevation myocardial infarction post-PCI. ${ }^{67}$ Conventionally, the antiplatelet function of aspirin and clopidogrel (reactivity to agonist) and the anticoagulant ability of rivaroxaban have been measured separately. However, all of these drugs are used for the same purpose: to inhibit thrombosis. Many clinical trials have confirmed that combined use of these drugs will decrease vascular events, but will increase bleeding risk. Quantitatively evaluating the comprehensive antithrombotic potential of these drugs may be useful information for determining an antithrombotic therapy that is appropriate for individual patients.

\section{Assessment of Total Thrombogenicity and Periprocedural Bleeding Events in Patients undergoing Catheter Ablation for AF Treated with Anticoagulants}

Anticoagulants are useful agents for preventing cerebrovascular events in patients with AF. A previous study reported that warfarin reduced the risk of stroke by $64 \%$ compared with placebo. ${ }^{68}$ DOACs have been clinically used in recent years for the prevention of cerebrovascular events in patients with nonvalvular AF. Importantly, accumulating clinical and experimental evidence indicates that DOACs, such as dabigatran, ${ }^{16}$ apixaban, ${ }^{17}$ rivaroxaban, ${ }^{18}$ and edoxaban, ${ }^{19}$ in addition to warfarin, can reduce the likelihood of cerebrovascular events in nonvalvular AF patients. A recent network meta-analysis demonstrated that DOACs appear to be at least equivalent to warfarin at preventing stroke in AF patients and to carry a reduced risk of bleeding. ${ }^{69}$

DOACs are innovative drugs that have resolved complex patient management issues associated with the administration of warfarin alone, such as frequent blood sampling, diet restriction, and drug interactions. However, there is no definitive tool for monitoring the anticoagulant effects of DOACs, even though some patients suffer bleeding complications due to excessively high blood concentrations of DOACs. ${ }^{70,71}$ Routine coagulation test parameters, such as the PT-international normalized ratio or APTT may be problematic for monitoring the anticoagulant effects of DOACs because individual DOACs have different characteristic chemical structures and different pharmacokinetic profiles (e.g., plasma half-life and tissue penetration rate). ${ }^{72}$ In the study of Ito et al, blood samples of AF patients undergoing catheter ablation (CA) were evaluated with AR chip. ${ }^{73}$ Blood samples obtained on the day of CA (anticoagulant-free point), and 3 days and 1 month after CA were evaluated using T-TAS to measure AR-AUC levels in two groups: those treated with warfarin and those treated with DOACs. The findings were: (1) AR-AUC levels were similar in the two groups on the day of CA; (2) AR-AUC levels were significantly lower in the two groups at 3 days and 1 month after CA than on the day of CA; and (3) AR-AUC level on the day of CA and 3 days after $C A$ was a significant predictor of periprocedural bleeding events by receiver-operating characteristic 
analysis. In this study, few AF patients developed thrombotic events after $C A$, possibly because of the continuous anticoagulant therapies after CA. While T-TAS is almost certainly expected to have clinical value, large-scale clinical studies are needed to confirm the usefulness of this device for monitoring thrombotic and bleeding events after CA.

\section{Prophylaxis of VTE by Edoxaban after Total Knee Arthroplasty}

In orthopedic surgery, VTE often occurs during the perioperative period of total hip arthroplasty, total knee arthroplasty (TKA), and hip fracture surgery. Many cases are fatal once pulmonary thromboembolism occurs. Western ${ }^{74}$ and Japanese ${ }^{75}$ guidelines for the diagnosis, treatment, and prevention of VTE recommend physiotherapy or anticoagulation therapy for preventing VTE in high-risk patients, including after TKA. In a recent clinical study, ${ }^{76,77} 38$ patients were randomly assigned to the physiotherapy group $(N=19)$ or the physiotherapy plus $30 \mathrm{mg} /$ day of edoxaban group $(N=19)$. As a result, the combination therapy significantly reduced the incidence of VTE after TKA compared to monotherapy, with the significant decrease of AR-AUC levels in the combination therapy group 7 days after TKA than before TKA.

\section{Limitations}

T-TAS is suitable to measure platelet function or coagulation as a global assay but not able to specially evaluate the activity of a pathway that may be targeted by an antithrombotic agent. For example, using T-TAS, it is possible to identify that overall primary hemostatic function has been impaired, but it is difficult to determine which drug is responsible for low PLAUC levels in patients treated with DAPT, aspirin, or a $\mathrm{P}_{2} \mathrm{Y}_{12}$ receptor blocker. The soluble agonist-based VerifyNow and Multiplate systems are specific for certain platelet activation pathways but are not suitable to monitor global platelet function or overall primary hemostatic function in patients treated with DAPT. The combined use of the T-TAS and VerifyNow (or Multiplate) systems might be beneficial to determine both the specific antiplatelet drug effects on their targeted platelet activation pathways, and also their combined effect on overall primary hemostatic function in patients treated with DAPT.

An additional limitation is that a PL-AUC or AR-AUC threshold associated with thrombotic risk has not yet been conclusively identified. The recent published clinical studies were performed at a single center on a relatively small number of patients and may therefore be underpowered for the accurate detection of differences in thrombotic event rates. Therefore,

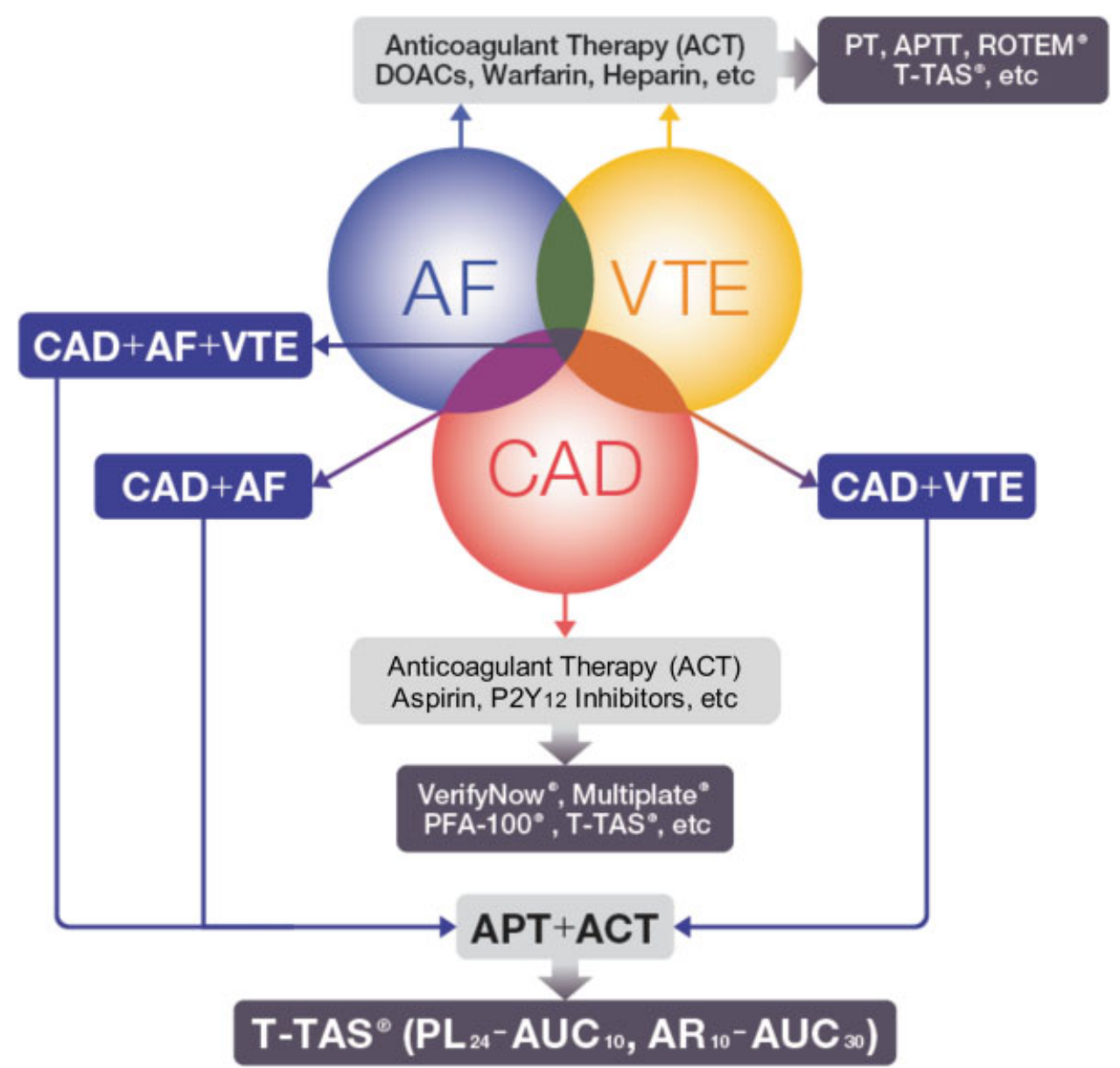

Fig. 2 Overview of the current methods for evaluating antiplatelet and anticoagulant therapies, including Total Thrombus-Formation Analysis System (T-TAS), in various cardiovascular diseases. AF, atrial fibrillation; APTT, activated partial thromboplastin time; CAD, coronary artery disease; DOACs, direct oral anticoagulants; PT, prothrombin time; VTE: venous thromboembolism. 
additional studies in larger populations are needed to further examine the relationship between PL-AUC or AR-AUC level measured by T-TAS and an increased risk of thrombotic cardiovascular events, as well as to further evaluate the association between T-TAS results and bleeding events.

\section{Conclusion and Future Perspectives}

As summarized in this review, recent clinical studies suggest that T-TAS is suitable for assessing the effects of different antiplatelet therapies such as aspirin and thienopyridines, and anticoagulant therapies such as warfarin and DOACs (dabigatran, rivaroxaban, apixaban, and edoxaban). Further, PL chip and AR chip AUCs measured by the T-TAS might be useful for predicting periprocedural bleeding events after various types of cardiovascular interventions.

As shown in - Fig. 2, various antithrombotic strategies such as antiplatelet therapies (aspirin and $\mathrm{P}_{12} \mathrm{Y}_{12}$ inhibitors) for CAD and anticoagulant therapies (DOACs, warfarin, and heparin) for AF or VTE are clinically used to inhibit the cascade of arterial or venous thrombosis in cardiovascular diseases. However, a combination of antiplatelet and anticoagulant therapies must be selected for patients with CAD complicated with AF and/or VTE. Several diagnostic devices for monitoring antiplatelet treatments, such as VerifyNow, Multiplate, and PFA-100, and devices and parameters for monitoring anticoagulant treatments, such as PT, APTT, and ROTEM, are limited when measuring whole blood thrombogenicity in patients receiving combination antiplatelet and anticoagulant therapies. T-TAS parameters (PL-AUC and ARAUC) might be more effective for evaluating the total antithrombotic effects of combination antithrombotic agents in patients with various cardiovascular diseases.

Recent randomized clinical trials such as PIONEER AF-PCl ${ }^{78}$ or RE-DUAL PCI ${ }^{79}$ have demonstrated the efficacy and safety of combined antiplatelet therapy and a DOAC (rivaroxaban and dabigatran, respectively) in nonvalvular AF patients who have undergone PCI. In the PIONEER AF-PCI trial, administration of either low-dose rivaroxaban plus a $\mathrm{P}_{2} \mathrm{Y}_{12}$ receptor inhibitor for 12 months or very low-dose rivaroxaban plus DAPT for 1,6 , or 12 months was associated with a lower rate of clinically significant bleeding than standard therapy with a vitamin $\mathrm{K}$ antagonist plus DAPT for 1,6 , or 12 months. In the RE-DUAL PCI trial, the risk of bleeding was lower among CAD patients with $\mathrm{AF}$ who had undergone $\mathrm{PCl}$ and received dual therapy with dabigatran and a $\mathrm{P}_{2} \mathrm{Y}_{12}$ receptor inhibitor than among those who received triple therapy comprising warfarin, a $\mathrm{P}_{2} \mathrm{Y}_{12}$ receptor inhibitor, and aspirin. However, these studies lacked a monitoring system to evaluate the efficacy and safety of the combination of antiplatelet and anticoagulation therapies. T-TAS may be a useful system for evaluating the potential efficacy and safety of antithrombotic therapies in various cardiovascular diseases.

\section{Funding}

This study was supported in part by Grants-in-Aid for Scientific Research (\#15K09089) from the Ministry of Education, Culture, Sports, Science and Technology of Japan.

\section{Conflict of Interest}

K.K. has received grants from Bayer Yakuhin, Ltd., DaiichiSankyo Co., Ltd., Novartis Pharma AG., and SBI Pharma K. K.; and honoraria from Bayer Yakuhin, Ltd. and DaiichiSankyo Co., Ltd. K.T. has received honoraria from Amgen, Astellas BioPharma K.K., Bayer Yakuhin, Ltd., DaiichiSankyo Co., Ltd., MSD K.K., and Sanofi K.K.; and has received grants from AstraZeneca K.K., Astellas Pharma Inc., Bayer Yakuhin, Ltd., Boehringer Ingelheim Japan, Boston Scientific Japan K.K., Chugai Pharmaceutical Co., Ltd., Daiichi-Sankyo Co., Ltd., Eisai Co., Ltd., Kowa Pharmaceutical Co. Ltd., Mitsubishi Tanabe Pharma, MSD K.K., Pfizer Japan Inc., Sanofi K.K., Shionogi \& Co., Ltd., and Takeda Pharmaceutical Co., Ltd. J.R.D. has received consulting fees from Fujimori Kogyo, Co, Ltd. K.H. is an employee of Fujimori Kogyo, Co., Ltd.

\section{Acknowledgments}

The authors thank Yuichiro Arima, Daisuke Sueta, Miwa Ito, Masanobu Ishii, Yu Oimatsu, Tatsuro Mitsuse, Nobuhiro Nakanishi, Satomi Iwashita, and Aya Takahashi of the Department of Cardiovascular Medicine, Graduate School of Medical Sciences, Kumamoto University, Kumamoto, Japan, for their excellent support in the research. The authors also thank Tomoko Ohnishi of the Research Institute, Fujimori Kogyo Co., Yokohama, Kanagawa, Japan, for her excellent technical support and advice.

\section{References}

1 Toschi V, Gallo R, Lettino M, et al. Tissue factor modulates the thrombogenicity of human atherosclerotic plaques. Circulation 1997;95(03):594-599

2 Rentrop KP. Thrombi in acute coronary syndromes: revisited and revised. Circulation 2000;101(13):1619-1626

3 Davies MJ. Stability and instability: two faces of coronary atherosclerosis. The Paul Dudley White Lecture 1995. Circulation 1996; 94(08):2013-2020

4 Leon MB, Baim DS, Popma JJ, et al; Stent Anticoagulation Restenosis Study Investigators. A clinical trial comparing three antithrombotic-drug regimens after coronary-artery stenting. N Engl J Med 1998;339(23):1665-1671

5 Urban P, Macaya C, Rupprecht HJ, et al. Randomized evaluation of anticoagulation versus antiplatelet therapy after coronary stent implantation in high-risk patients: the multicenter aspirin and ticlopidine trial after intracoronary stenting (MATTIS). Circulation 1998;98(20):2126-2132

6 Yusuf S, Zhao F, Mehta SR, Chrolavicius S, Tognoni G, Fox KK; Clopidogrel in Unstable Angina to Prevent Recurrent Events Trial Investigators. Effects of clopidogrel in addition to aspirin in patients with acute coronary syndromes without ST-segment elevation. N Engl J Med 2001;345(07):494-502

7 Mehta SR, Yusuf S, Peters RJ, et al; Clopidogrel in Unstable angina to prevent Recurrent Events trial (CURE) Investigators. Effects of pretreatment with clopidogrel and aspirin followed by longterm therapy in patients undergoing percutaneous coronary intervention: the PCI-CURE study. Lancet 2001;358(9281): 527-533

8 Gerschutz GP, Bhatt DL; Clopidogrel in Unstable Angina to Prevent Recurrent Events study. The Clopidogrel in Unstable Angina to Prevent Recurrent Events (CURE) study: to what extent should the results be generalizable? Am Heart J 2003; 145(04):595-601 
9 Wiviott SD, Braunwald E, McCabe CH, et al; TRITON-TIMI 38 Investigators. Prasugrel versus clopidogrel in patients with acute coronary syndromes. N Engl J Med 2007;357(20):2001-2015

10 Saito S, Isshiki T, Kimura T, et al. Efficacy and safety of adjusteddose prasugrel compared with clopidogrel in Japanese patients with acute coronary syndrome: the PRASFIT-ACS study. Circ J 2014;78(07):1684-1692

11 Isshiki T, Kimura T, Ogawa $\mathrm{H}$, et al; PRASFIT-Elective Investigators. Prasugrel, a third-generation P2Y12 receptor antagonist, in patients with coronary artery disease undergoing elective percutaneous coronary intervention. Circ J 2014;78(12):2926-2934

12 Airoldi F, Colombo A, Morici N, et al. Incidence and predictors of drug-eluting stent thrombosis during and after discontinuation of thienopyridine treatment. Circulation 2007;116(07):745-754

13 Iakovou I, Schmidt T, Bonizzoni E, et al. Incidence, predictors, and outcome of thrombosis after successful implantation of drugeluting stents. JAMA 2005;293(17):2126-2130

14 Chen ZM, Jiang LX, Chen YP, et al; COMMIT (ClOpidogrel and Metoprolol in Myocardial Infarction Trial) collaborative group. Addition of clopidogrel to aspirin in 45,852 patients with acute myocardial infarction: randomised placebo-controlled trial. Lancet 2005;366(9497):1607-1621

15 Sabatine MS, Cannon CP, Gibson CM, et al; CLARITY-TIMI 28 Investigators. Addition of clopidogrel to aspirin and fibrinolytic therapy for myocardial infarction with ST-segment elevation. N Engl J Med 2005;352(12):1179-1189

16 Connolly SJ, Ezekowitz MD, Yusuf S, et al; RE-LY Steering Committee and Investigators. Dabigatran versus warfarin in patients with atrial fibrillation. N Engl J Med 2009;361(12): 1139-1151

17 Granger CB, Alexander JH, McMurray JJ, et al; ARISTOTLE Committees and Investigators. Apixaban versus warfarin in patients with atrial fibrillation. N Engl J Med 2011;365(11):981-992

18 Patel MR, Mahaffey KW, Garg J, et al; ROCKET AF Investigators. Rivaroxaban versus warfarin in nonvalvular atrial fibrillation. N Engl J Med 2011;365(10):883-891

19 Giugliano RP, Ruff CT, Braunwald E, et al; ENGAGE AF-TIMI 48 Investigators. Edoxaban versus warfarin in patients with atrial fibrillation. N Engl J Med 2013;369(22):2093-2104

20 Agnelli G, Buller HR, Cohen A, et al; AMPLIFY Investigators. Oral apixaban for the treatment of acute venous thromboembolism. $\mathrm{N}$ Engl J Med 2013;369(09):799-808

21 Nakamura M, Nishikawa M, Komuro I, et al. Apixaban for the treatment of Japanese subjects with acute venous thromboembolism (AMPLIFY-J Study). Circ J 2015;79(06):1230-1236

22 Schulman S, Kearon C, Kakkar AK, et al; RE-COVER Study Group. Dabigatran versus warfarin in the treatment of acute venous thromboembolism. N Engl J Med 2009;361(24):2342-2352

23 Bauersachs R, Berkowitz SD, Brenner B, et al; EINSTEIN Investigators. Oral rivaroxaban for symptomatic venous thromboembolism. N Engl J Med 2010;363(26):2499-2510

24 Büller HR, Prins MH, Lensin AW, et al; EINSTEIN-PE Investigators. Oral rivaroxaban for the treatment of symptomatic pulmonary embolism. N Engl J Med 2012;366(14):1287-1297

25 Büller HR, Décousus H, Grosso MA, et al; Hokusai-VTE Investigators. Edoxaban versus warfarin for the treatment of symptomatic venous thromboembolism. N Engl J Med 2013;369(15):1406-1415

26 Lordkipanidzé M, Pharand C, Schampaert E, Turgeon J, Palisaitis DA, Diodati JG. A comparison of six major platelet function tests to determine the prevalence of aspirin resistance in patients with stable coronary artery disease. Eur Heart J 2007;28(14): $1702-1708$

27 Lordkipanidzé M, Pharand C, Nguyen TA, Schampaert E, Palisaitis DA, Diodati JG. Comparison of four tests to assess inhibition of platelet function by clopidogrel in stable coronary artery disease patients. Eur Heart J 2008;29(23):2877-2885

28 Grove EL, Hvas AM, Johnsen HL, et al. A comparison of platelet function tests and thromboxane metabolites to evaluate aspirin response in healthy individuals and patients with coronary artery disease. Thromb Haemost 2010;103(06):1245-1253

29 Price MJ. Bedside evaluation of thienopyridine antiplatelet therapy. Circulation 2009;119(19):2625-2632

30 Harle CC. Point-of-care platelet function testing. Semin Cardiothorac Vasc Anesth 2007;11(04):247-251

31 Harrison P. Assessment of platelet function in the laboratory. Hamostaseologie 2009;29(01):25-31

32 Smith JW, Steinhubl SR, Lincoff AM, et al. Rapid platelet-function assay: an automated and quantitative cartridge-based method. Circulation 1999;99(05):620-625

33 Ganter MT, Hofer CK. Coagulation monitoring: current techniques and clinical use of viscoelastic point-of-care coagulation devices. Anesth Analg 2008;106(05):1366-1375

34 Gerotziafas GT, Elalamy I, Depasse F, Perzborn E, Samama MM. In vitro inhibition of thrombin generation, after tissue factor pathway activation, by the oral, direct factor Xa inhibitor rivaroxaban. J Thromb Haemost 2007;5(04):886-888

35 Hosokawa K, Ohnishi T, Fukasawa M, et al. A microchip flowchamber system for quantitative assessment of the platelet thrombus formation process. Microvasc Res 2012;83(02): 154-161

36 Hosokawa $\mathrm{K}$, Ohnishi T, Kondo T, et al. A novel automated microchip flow-chamber system to quantitatively evaluate thrombus formation and antithrombotic agents under blood flow conditions. J Thromb Haemost 2011;9(10):2029-2037

37 Sueta D, Kaikita K, Okamoto N, et al. A novel quantitative assessment of whole blood thrombogenicity in patients treated with a non-vitamin K oral anticoagulant. Int J Cardiol 2015;197:98-100

38 Yamaguchi Y, Moriki T, Igari A, et al. Studies of a microchip flowchamber system to characterize whole blood thrombogenicity in healthy individuals. Thromb Res 2013;132(02):263-270

39 Sueta D, Kaikita K, Ogawa H. Letter by Sueta et al Regarding Article, "Urgent Need to Measure Effects of Direct Oral Anticoagulants". Circulation 2016;134(21):e496-e497

40 Hosokawa K, Ohnishi T, Sameshima H, et al. Comparative evaluation of direct thrombin and factor Xa inhibitors with antiplatelet agents under flow and static conditions: an in vitro flow chamber model. PLoS One 2014;9(01):e86491

41 Hosokawa K, Ohnishi T, Miura N, et al. Antithrombotic effects of PAR1 and PAR4 antagonists evaluated under flow and static conditions. Thromb Res 2014;133(01):66-72

42 Arima Y, Kaikita K, Ishii M, et al. Assessment of platelet-derived thrombogenicity with the total thrombus-formation analysis system in coronary artery disease patients receiving antiplatelet therapy. J Thromb Haemost 2016;14(04):850-859

43 Yasue H, Ogawa H, Tanaka H, et al; Japanese Antiplatelets Myocardial Infarction Study (JAMIS) Investigators. Effects of aspirin and trapidil on cardiovascular events after acute myocardial infarction. Am J Cardiol 1999;83(09):1308-1313

44 Frelinger AL III, Bhatt DL, Lee RD, et al. Clopidogrel pharmacokinetics and pharmacodynamics vary widely despite exclusion or control of polymorphisms (CYP2C19, ABCB1, PON1), noncompliance, diet, smoking, co-medications (including proton pump inhibitors), and pre-existent variability in platelet function. J Am Coll Cardiol 2013;61(08):872-879

45 Angiolillo DJ. Variability in responsiveness to oral antiplatelet therapy. Am J Cardiol 2009;103(3, Suppl):27A-34A

46 Hollopeter G, Jantzen HM, Vincent D, et al. Identification of the platelet ADP receptor targeted by antithrombotic drugs. Nature 2001;409(6817):202-207

47 Mega JL, Close SL, Wiviott SD, et al. Cytochrome p-450 polymorphisms and response to clopidogrel. N Engl J Med 2009;360 (04):354-362

48 Angiolillo DJ, Bates ER, Bass TA. Clinical profile of prasugrel, a novel thienopyridine. Am Heart J 2008;156(2 Suppl):S16-S22

49 Ogawa H, Hokimoto S, Kaikita K, et al. Current status and prospects of antiplatelet therapy in percutaneous coronary 
intervention in Japan: focus on adenosine diphosphate receptor inhibitors. J Cardiol 2011;58(01):6-17

50 Ono T, Kaikita K, Hokimoto S, et al. Determination of cut-off levels for on-clopidogrel platelet aggregation based on functional CYP2C19 gene variants in patients undergoing elective percutaneous coronary intervention. Thromb Res 2011;128(06):e130-e136

51 Kaikita K, Ono T, Iwashita S, et al. Impact of CYP2C19 polymorphism on platelet function tests and coagulation and inflammatory biomarkers in patients undergoing percutaneous coronary intervention. J Atheroscler Thromb 2014;21(01):64-76

52 Kaikita K, Yoshimura H, Ishii M, et al; CALDERA-GENE Investigators. Tailored adjunctive cilostazol therapy based on CYP2C19 genotyping in patients with acute myocardial infarction - the CALDERA-GENE study. Circ J 2018;82(06):1517-1525

53 Yamamoto K, Hokimoto S, Chitose T, et al. Impact of CYP2C19 polymorphism on residual platelet reactivity in patients with coronary heart disease during antiplatelet therapy. J Cardiol 2011;57(02):194-201

54 Price MJ, Angiolillo DJ, Teirstein PS, et al. Platelet reactivity and cardiovascular outcomes after percutaneous coronary intervention: a time-dependent analysis of the Gauging Responsiveness with a VerifyNow P2Y12 assay: Impact on Thrombosis and Safety (GRAVITAS) trial. Circulation 2011;124(10):1132-1137

55 Hosokawa K, Ohnishi T, Sameshima H, et al. Analysing responses to aspirin and clopidogrel by measuring platelet thrombus formation under arterial flow conditions. Thromb Haemost 2013; 109(01):102-111

56 Yamazaki M, Ohnishi T, Hosokawa K, et al. Measurement of residual platelet thrombogenicity under arterial shear conditions in cerebrovascular disease patients receiving antiplatelet therapy. J Thromb Haemost 2016;14(09):1788-1797

57 Kwok CS, Khan MA, Rao SV, et al. Access and non-access site bleeding after percutaneous coronary intervention and risk of subsequent mortality and major adverse cardiovascular events: systematic review and meta-analysis. Circ Cardiovasc Interv 2015;8(04):e001645

58 Rao SV, Dai D, Subherwal S, et al. Association between periprocedural bleeding and long-term outcomes following percutaneous coronary intervention in older patients. JACC Cardiovasc Interv 2012;5(09):958-965

59 Feit F, Voeltz MD, Attubato MJ, et al. Predictors and impact of major hemorrhage on mortality following percutaneous coronary intervention from the REPLACE-2 Trial. Am J Cardiol 2007;100(09):1364-1369

60 Kwok CS, Rao SV, Myint PK, et al. Major bleeding after percutaneous coronary intervention and risk of subsequent mortality: a systematic review and meta-analysis. Open Heart 2014;1(01):e000021

61 Kinnaird TD, Stabile E, Mintz GS, et al. Incidence, predictors, and prognostic implications of bleeding and blood transfusion following percutaneous coronary interventions. Am J Cardiol 2003; 92(08):930-935

62 Subherwal S, Peterson ED, Dai D, et al. Temporal trends in and factors associated with bleeding complications among patients undergoing percutaneous coronary intervention: a report from the National Cardiovascular Data CathPCI Registry. J Am Coll Cardiol 2012;59(21):1861-1869

63 Vora AN, Rao SV. Bleeding complications after PCI and the role of transradial access. Curr Treat Options Cardiovasc Med 2014;16 (05):305

64 Mehran R, Rao SV, Bhatt DL, et al. Standardized bleeding definitions for cardiovascular clinical trials: a consensus report from the Bleeding Academic Research Consortium. Circulation 2011; 123(23):2736-2747

65 Saito S, Isshiki T, Kimura T, et al; PRASFIT-ACS and PRASFITElective Investigators. Impact of arterial access route on bleeding complications in Japanese patients undergoing percutaneous coronary intervention- insight from the PRASFIT trial. Circ J 2015;79(09):1928-1937

66 Oimatsu Y, Kaikita K, Ishii M, et al. Total thrombus-formation analysis system predicts periprocedural bleeding events in patients with coronary artery disease undergoing percutaneous coronary intervention. J Am Heart Assoc 2017;6(04):e005263

67 Borst $\mathrm{O}$, Münzer P, Alnaggar N, et al. Inhibitory mechanisms of very low-dose rivaroxaban in non-ST-elevation myocardial infarction. Blood Adv 2018;2(06):715-730

68 Hart RG, Pearce LA, Aguilar MI. Meta-analysis: antithrombotic therapy to prevent stroke in patients who have nonvalvular atrial fibrillation. Ann Intern Med 2007;146(12):857-867

69 López-López JA, Sterne JAC, Thom HHZ, et al. Oral anticoagulants for prevention of stroke in atrial fibrillation: systematic review, network meta-analysis, and cost effectiveness analysis. BMJ 2017; 359:j5058

70 Komori M, Yasaka M, Kokuba K, et al. Intracranial hemorrhage during dabigatran treatment. Circ J 2014;78(06):1335-1341

71 Suzuki S, Sagara K, Otsuka T, et al. "Blue letter effects": changes in physicians' attitudes toward dabigatran after a safety advisory in a specialized hospital for cardiovascular care in Japan. J Cardiol 2013;62(06):366-373

72 Ogawa S, Koretsune Y, Yasaka M, et al. Antithrombotic therapy in atrial fibrillation: evaluation and positioning of new oral anticoagulant agents. Circ J 2011;75(07):1539-1547

73 Ito M, Kaikita K, Sueta D, et al. Total Thrombus-formation Analysis System (T-TAS) can predict periprocedural bleeding events in patients undergoing catheter ablation for atrial fibrillation. J Am Heart Assoc 2016;5(01):e002744

74 Guyatt GH, Akl EA, Crowther M, Gutterman DD, Schuünemann HJ; American College of Chest Physicians Antithrombotic Therapy and Prevention of Thrombosis Panel. Executive summary: antithrombotic therapy and prevention of thrombosis: American College of Chest Physicians evidence-based clinical practice guidelines. Chest 2012;141(2, Suppl):7S-47S

75 Group JCSJW; JCS Joint Working Group. Guidelines for the diagnosis, treatment and prevention of pulmonary thromboembolism and deep vein thrombosis (JCS 2009). Circ J 2011;75(05): 1258-1281

76 Sueta D, Kaikita K, Okamoto N, et al. Efficacy study of the combination of edoxaban and physiotherapy on the prevention of venous-thromboembolism in patients after total knee arthroplasty (ESCORT-TKA trial): study protocol for a randomized controlled trial. Clin Trials Regul Sci Cardiol 2016;19:1-4

77 Sueta D, Kaikita K, Okamoto N, et al; ESCORT-TKA Study Investigators. Edoxaban enhances thromboprophylaxis by physiotherapy after total knee arthroplasty- the randomized controlled ESCORT-TKA trial. Circ J 2018;82(02):524-531

78 Gibson CM, Mehran R, Bode C, et al. Prevention of bleeding in patients with atrial fibrillation undergoing PCI. N Engl J Med 2016;375(25):2423-2434

79 Cannon CP, Bhatt DL, Oldgren J, et al; RE-DUAL PCI Steering Committee and Investigators. Dual antithrombotic therapy with dabigatran after PCI in atrial fibrillation. N Engl J Med 2017;377 (16):1513-1524 